\title{
Aprendendo progressões aritmética e geométrica com juros simples e compostos*
}

\author{
Joelson Vitor Rolino $^{\dagger} \quad$ Dais C. Afini $^{\dagger} \quad$ José C. de Souza Junior $^{-}$ \\ Universidade Federal de Alfenas- Instituto de Ciências Exatas \\ 37130-000, Alfenas, MG \\ E-mail: joelsonrollino@hotmail, daisafini@gmail.com, jcsouzajr@uol.com.br.
}

\section{RESUMO}

A evolução das tecnologias de informação e da comunicação tem proporcionado uma alternativa no campo educacional, visto que com o avanço da internet, a sociedade tem aprimorado os meios de comunicação, mobilidade e transmissão da informação. Como os alunos são nativos digitais esse ambiente propiciado por tais recursos tecnológicos facilita a aprendizagem, pois garante ao aluno a possibilidade de aprender em seu próprio tempo, criar suas estratégias de estudo e observar seu desenvolvimento. Um bom exemplo é citado em [3] no qual os objetos de aprendizagem no formato de videoaulas acompanham a necessidade de cada um, pois é possível que cada indivíduo assista de acordo com sua necessidade.

Entretanto, há dificuldade em encontrar materiais que auxiliem nas atividades que possam ser realizadas em ambientes virtuais de aprendizagem [4]. Desse modo, segundo o mesmo autor os ambientes virtuais de aprendizagem podem ser elaborados com base na Teoria da Atividade de Engeström, pois esta aborda o sentido de atividade coletiva e com a elaboração do ciclo expansivo possibilita uma maior interação entre a transformação ou criação do conhecimento, despertando a capacidade de análise, elaboração e solução de um determinado problema. O ciclo expansivo de Engeström [1] compreende sete etapas: questionar, analisar, modelar, examinar, implementar, refletir e consolidar.

A matemática financeira é apresentada nos livros didáticos por meio de fórmulas e definições, se resumindo ao estudo de descontos, lucros, juros simples e compostos. Dessa forma, não é explorada a relação entre a matemática financeira e outros conteúdos de matemática como progressão aritmética, geométrica e funções [2].Dessa forma, o objetivo desse trabalho é apresentar um objeto de aprendizagem no formato de videoaula fundamentada na Teoria da Atividade e planejada de acordo com as etapas do ciclo expansivo de Engeström para o estudo de progressões aritmética e geométrica aplicada à matemática financeira.

$\mathrm{O}$ ensino-aprendizagem através de objetos de aprendizagem segue os princípios da teoria de $\mathrm{Vy}$ gotsky no que diz respeito ao processo de mediação, visto que existe um agente mediador do conhecimento representado pela fala que garante a interação entre o agente conversacional e o aluno. Os recursos gráficos dinâmicos, como setas, sublinhados, marcações simbólicas atuam como signos que ficam registrados e organizados em estruturas no interior de cada sujeito. E os programas computacionais de matemática dinâmica atuam como instrumentos de mediação. O processo de mediação deve ocorrer de forma sistematizada, por isso os objetos de aprendizagem de matemática financeira seguem uma sequência didática que valoriza o questionamento, a investigação, a experimentação, o levantamento e a comprovação de hipóteses para a construção do conhecimento.

Assim, na primeira etapa é apresentada uma situação-problema referente à aplicação de um capital inicial em uma caderneta de poupança em regime de juros simples. Em seguida, é apresentada outra aplicação financeira em que o mesmo capital inicial é aplicado em um título de capitalização com a

\footnotetext{
${ }^{*}$ O presente trabalho foi realizado com apoio financeiro da Fundação de Amparo a Pesquisa do Estado de Minas Gerais (FAPEMIG) e do Programa Institucional de Bolsa de Iniciação à Docência (PIBID), da Coordenação de Aperfeiçoamento de Pessoal de Nível Superior (CAPES), Brasil.

${ }^{\dagger}$ Bolsistas de Iniciação à Docência PIBID/CAPES
} 
mesma taxa de juros, porém seguindo o regime de capitalização de juros compostos durante o mesmo período de tempo da primeira aplicação. A partir desta informação o aluno é incentivado a analisar as duas situações e propor hipóteses, como resultado da segunda etapa do ciclo expansivo. Na terceira etapa, com base nas hipóteses levantadas e nos modelos conhecidos de sequências numéricas, o aluno deve buscar um modelo que satisfaça a sequência de montantes gerada pelos regimes de capitalização simples e compostos.

$\mathrm{Na}$ quarta etapa, o aluno deve examinar o novo modelo construído, verificando se este satisfaz as condições iniciais do problema em questão. Esse modelo deve ser implementado com as definições de matemática financeira a qual corresponde à quinta etapa. A fim de que o aluno a partir da construção deste novo conhecimento possa refletir sobre a situação-problema inicial como sugere a sexta etapa. Finalmente na sétima etapa os alunos chegarão a conclusão de que os juros simples se comportam como uma progressão aritmética e os juros compostos como uma progressão geométrica.

Assim, este objeto de aprendizagem é parte de um projeto de videoaulas de funções logarítmicas, que segue também o ciclo expansivo. Dessa forma, se encerra o ciclo expansivo para o ensino-aprendizagem de matemática financeira e preparando o para outros tópicos matemáticos como logaritmo, que será utilizado no cálculo do período de tempo de uma determina aplicação conhecendo-se o capital inicial, a taxa de juros e o montante final. O material didático foi concebido à luz da Teoria da Atividade de Engeström, entendendo que o processo de construção do conhecimento ocorre de fora para dentro a medida que o aluno se comunica e atua sobre o meio resolvendo problemas, utilizando instrumentos e signos internalizados.

Portanto, o ciclo expansivo embasado na Teoria da Atividade pode servir como uma metodologia facilitadora da aprendizagem. Visto que, os objetos de aprendizagem em formato de videoaulas respeitam o ritmo individual de estudo e permitem o retorno do aprendiz as etapas que não foram compreendidas, possibilitando uma revisão do conteúdo ainda não consolidado. Futuramente, as videoaulas serão apresentadas e validadas como objetos de aprendizagem através de uma aplicação sistematizada com alunos do ensino médio e professores em formação do curso de licenciatura em matemática.

Palavras-chave: Matemática Financeira, objetos de aprendizagem, Teoria da Atividade.

\section{Referências}

[1] Y. Engeström, Activity theory and individual and social transformation, em "Perspectives on activity theory" (Y. Engeström et al., ed.), MIT Press, Cambridge, 1999.

[2] R. C. N. Novaes, "Uma abordagem visual para o ensino de matemática financeira no ensino médio", Dissertação de Mestrado, IM-UFRJ, 2009.

[3] H. M. P. Oliveira, A. Cardoso, J.C. Souza Junior, Funções trigonométricas em vídeo aulas: possível contribuição para a aprendizagem, em "Encontro nacional de educação matemática", pp. 1-16, Curitiba, 2013.

[4] D. L. P. Souto, M. C. Borba, Miniciclo de aprendizagem expansiva em sistema Seres-humanoscom-mídias e o fazer matemática online, em "Encontro nacional de educação matemática", pp.1-16, Curitiba, 2013. 